\title{
Occurrence of green mold disease on Dictyophora rubrovolvata caused by Trichoderma koningiopsis
}

\author{
Xiaoyulong Chen ${ }^{1,2} \cdot$ Xiaohui Zhou $^{2} \cdot J_{\text {Jin }}$ Zhao $^{2} \cdot$ Xiaoli Tang $^{3} \cdot$ Matias Pasquali $^{5} \cdot$ Quirico Migheli $^{6} \cdot$ Gabriele Berg $^{4}$. \\ Tomislav Cernava ${ }^{2,4}$
}

Received: 29 August 2020 / Accepted: 18 March 2021 / Published online: 14 June 2021

(c) The Author(s) 2021

Keywords Dictyophora rubrovolvata $\cdot$ Mushroom disease $\cdot$ Green mold $\cdot$ Trichoderma koningiopsis

\begin{abstract}
Dictyophora rubrovolvata is an important edible mushroom that is widely cultivated in China. In 2019, a serious rot disease on D. rubrovolvata was observed in a mushroom production facility located in Ce Heng County, Southwest of Guizhou Province, China. The causal agent was identified as Trichoderma koningiopsis by amplification and sequencing of the internal transcribed spacer (ITS) region, the translation elongation factor 1-alpha (EF-1 $\alpha)$ gene, and the RNA polymerase II subunit (RPB2) gene followed by phylogenetic analysis. Koch's postulates were confirmed by a pathogenicity test that was conducted with healthy $D$. rubrovolvata, including re-isolation and identification. To our knowledge, this is worldwide the first report of T. koningiopsis as a pathogen on $D$. rubrovolvata causing green mold disease.
\end{abstract}

Xiaoyulong Chen

chenxiaoyulong@sina.cn

$\triangle$ Tomislav Cernava

tomislav.cernava@tugraz.at

1 College of Science, Tibet University, Lhasa 850012, China

2 Key Laboratory of Agricultural Microbiology, Guizhou University, Guiyang 550025, Guizhou, China

3 Guizhou Zhong Ao Ecosystem Service Center, Science Park, Guizhou University, Guiyang 550025, Guizhou, China

4 Institute of Environmental Biotechnology, Graz University of Technology, Petersgasse 12, 8010 Graz, Austria

5 DeFENS - Department of Food, Environmental and Nutritional Sciences, Università Degli Studi Di Milano, Via Celoria, 2, 20133 Milano, Italy

6 Dipartimento Di Agraria and NRD - Nucleo Di Ricerca Sulla Desertificazione, Università Degli Studi Di Sassari, Viale Italia 39, 07100 Sassari, Italy
In addition to crop production that provides the basic nutritional resources for humans, mushrooms have been widely cultivated in Asia for their nutritional value as well as for medicinal applications for over 2000 years (Wang et al. 2020). Dictyophora rubrovolvata M. Zang, D.G. Ji \& X.X. Liu, a saprophytic fungus which belongs to the Phallaceae family, is commonly known as "Zhu Sun" (bamboo fungi) in Chinese and "Kinugasatake" in Japanese. The use of this fungus as an edible mushroom can be traced back to the Tang Dynasty in China (Wang et al. 2018) . Due to its high nutritional, medical, and economic value, D. rubrovolvata is currently one of the main edible mushrooms commercially grown in Guizhou Province, China (Ye et al. 2016). It has a unique "umbrella-like" appearance and a crispy structure making it more and more popular in Chinese cuisine. Additionally, various polysaccharides with beneficial properties to health were found to be naturally present in $D$. rubrovolvata (Wang et al. 2018). This has recently attracted broader attention from consumers and caused an increased demand for traditional functional food. In March, 2019, a serious occurrence of rot disease on D. rubrovolvata was observed in Ceheng County, Guizhou Province, China. Green mold and wilt symptoms appeared on the surface of D. rubrovolvata during the early stages of cultivation (four months), causing direct death or preventing it from forming a sporocarp (Fig. 1A). The disease incidence was 60\%-70\% on the affected 5.33-ha growing area, causing a serious economic loss. This study was carried out to identify the causal agent of green mold on D. rubrovolvata and to provide relevant background for its sustainable management.

A total of 12 samples with symptomatic green mold and wilt symptoms were collected from $D$. rubrovolvata at different locations of a mushroom production facility located in Ceheng County, Southwest of Guizhou Province, China $\left(20^{\circ} 02^{\prime} 59^{\prime \prime} \mathrm{N}, 105^{\circ} 36^{\prime} 33^{\prime \prime} \mathrm{E}\right)$. The mushrooms were 

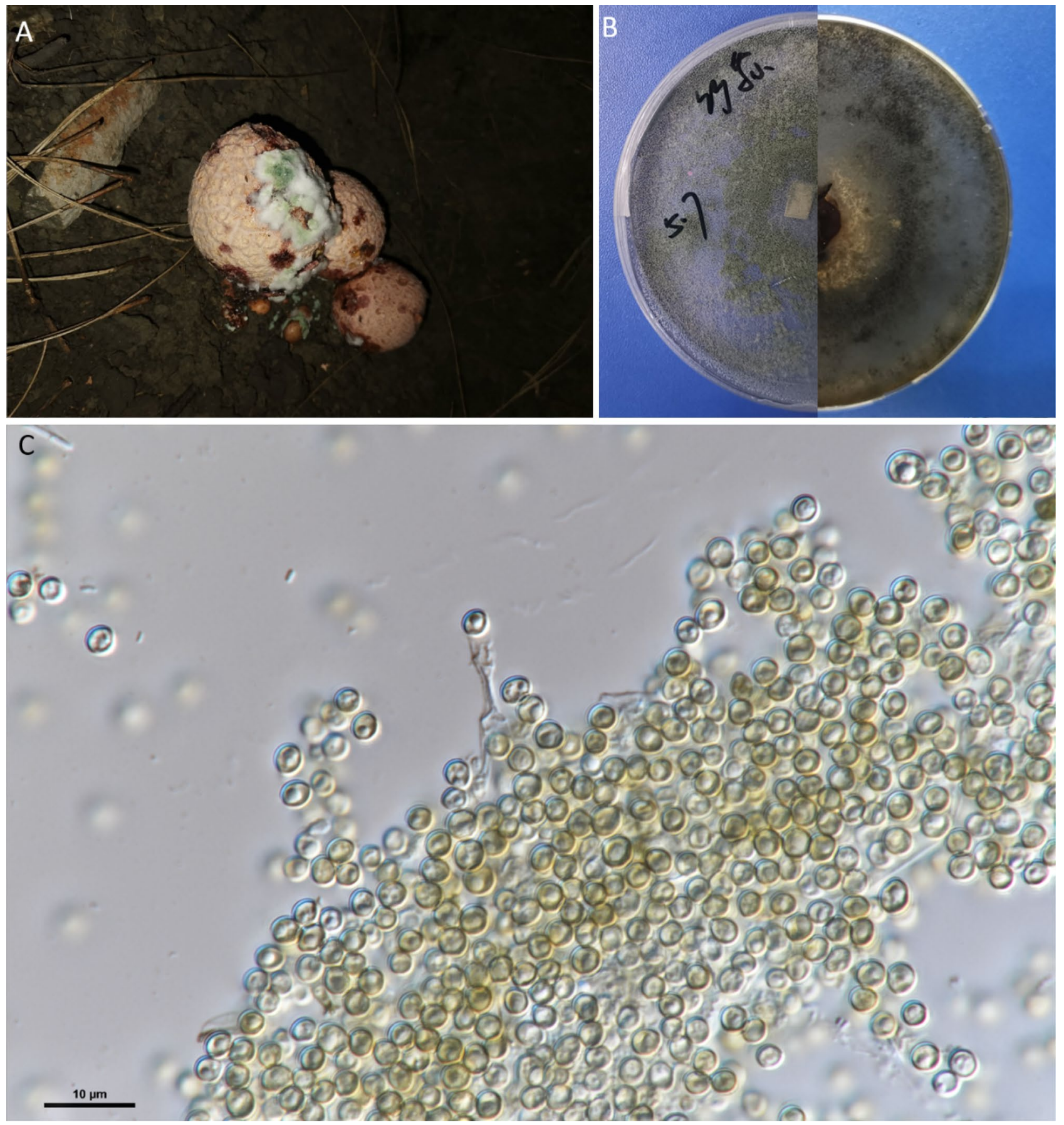

Fig. 1 Green mold of D. rubrovolvata caused by T. koningiopsis. A. Disease symptoms of T. koningiopsis on D. rubrovolvata; B. Colony of T. koningiopsis CXYL on potato dextrose agar (PDA) medium with the upper and lower Petri dish side pictured; C. Conidia of $T$. koningiopsis CXYL under white light microscopic observations

in the fungal pathogen collection of the Guizhou Provincial Key Laboratory for Agricultural Pest Management of the Mountainous Region (accession number: GZUPP-828). A representative isolate (hereafter referred to as CXYL) was used for microscopic observations where sporulating structures were mounted on a slide with distilled water. 
Observations were made with a Nikon Ni-E microscopic system (Nikon Inc, Melville NY). Measurements of conidiophores and conidia $(n=50)$ were performed using the software Nikon NIS Elements AR 4.50. The colonies of the fungal cultures were light green with a regular round shape at the early stage, and became dark green with fluffy hyphae after ten days, while the underside of the colony appeared pale yellow (Fig. 1B). Conidiophore branches arose at right angles, and primary branches arose singly or in pairs. Conidia were produced on the top of the phialides, with ellipsoidal to oblong shape, (2.1-) $3.5(-5.4) \times(1.4-) 2.8$ $(-3.8) \mu \mathrm{m}$ (Fig. 1C). Morphological characteristics of the isolates matched the description of the genus Trichoderma (Bissett 1991).

Genomic DNA of four representative isolates was extracted according to the manufacturer's instructions (Biomiga Fungal DNA Extraction Kit; CA, USA). Then, PCR amplifications were performed with primers ITS1 (5'-TCCGTAGGTGAACCTGCGG-3') and ITS4 (5'-TCC TCCGCTTATTGATATGC-3') for the internal transcribed spacer (ITS) region (White et al. 1990), primers EF1-728F (5'-CATCGAGAAGTTCGAGAAGG-3') and TEF1LLErev (5'-GCCATCCTTGGAGATACCAGC-3') for the translation elongation factor 1-alpha (EF-1 $\alpha)$ gene (Carbone and Kohn 1999), and primers RPB25F (5'-GAYGAYMGWG ATCAYTTYGG-3') and RBP2-7CR (5'-CCCATRGCT TGYTTRCCCA-3') for the RNA polymerase II subunit (RPB2) gene (Liu et al. 1999). The PCR amplification was carried out in a $25 \mu \mathrm{l}$ reaction mixture containing $1 \mu \mathrm{l}$ of DNA sample, $12.5 \mu 12 \times$ SanTaq PCR Mix (Sangon Biotech, Shanghai, China), $1 \mu \mathrm{l}$ of each primer $(100 \mu \mathrm{M})$, and $9.5 \mu \mathrm{l}$ nuclease-free water, The PCR conditions were as follows: initial denaturation at $94{ }^{\circ} \mathrm{C}$ for $3 \mathrm{~min}$, then denaturation at
$94{ }^{\circ} \mathrm{C}$ for $30 \mathrm{~s}$, annealing for $45 \mathrm{~s}$ with the corresponding temperatures $\left(55{ }^{\circ} \mathrm{C}\right.$ for ITS, $56{ }^{\circ} \mathrm{C}$ for $\mathrm{EF}-1 \alpha$, and $55^{\circ} \mathrm{C}$ for RPB2), extension at $72{ }^{\circ} \mathrm{C}$ for $1 \mathrm{~min}$, followed by 35 cycles, then a final extension for $3 \mathrm{~min}$. The obtained sequences were compared with other DNA sequences in the GenBank (NCBI) database. BLAST searches of the sequenced fragments resulted in the best match to $T$. koningii type specimen isolate ATCC 64,262 (ITS region: $99.81 \%$ identity to accession NR_138456), to T. koningiopsis strain UNISS 17b-36a (EF1- $\alpha$ : 98.75\% identity to accession EF488124.1), and to T. koningiopsis strain GJS 97-273 (RPB2: 98.31\% identity to accession FJ442795.1). Representative sequences of the sequenced DNA regions were deposited in GenBank (ITS region: MN108134; EF1- $\alpha$ : MN135988; RPB2: MT038997) and are included in Supplementary File 1 (FASTA format). In addition, a phylogenetic tree was constructed with MEGA 7 based on ITS region and EF1- $\alpha$ gene sequences in order to confirm that the representative isolate CXYL has a high genetic similarity to Trichoderma koningiopsis species (Fig. 2).

Koch's postulates were met to confirm the pathogenicity of this isolate on D. rubrovolvata. Briefly, spore suspensions of T. koningiopsis CXYL were prepared from onemonth-old colonies in $0.05 \%$ Tween buffer, and adjusted to a concentration of $1 \times 10^{6}$ conidia $/ \mathrm{mL}$. The suspension (500 $\mu \mathrm{L}$ for each treatment) was directly sprayed onto disease-free $D$. rubrovolvata grown in a greenhouse, and six mushrooms were inoculated in total. In addition, six D. rubrovolvata were spray-inoculated with $0.05 \%$ Tween buffer as a control. After 15 days, green mold appeared on all inoculated mushrooms. In contrast, no symptoms appeared in the control group that was treated with pathogen-free buffer. Pure cultures of T. koningiopsis

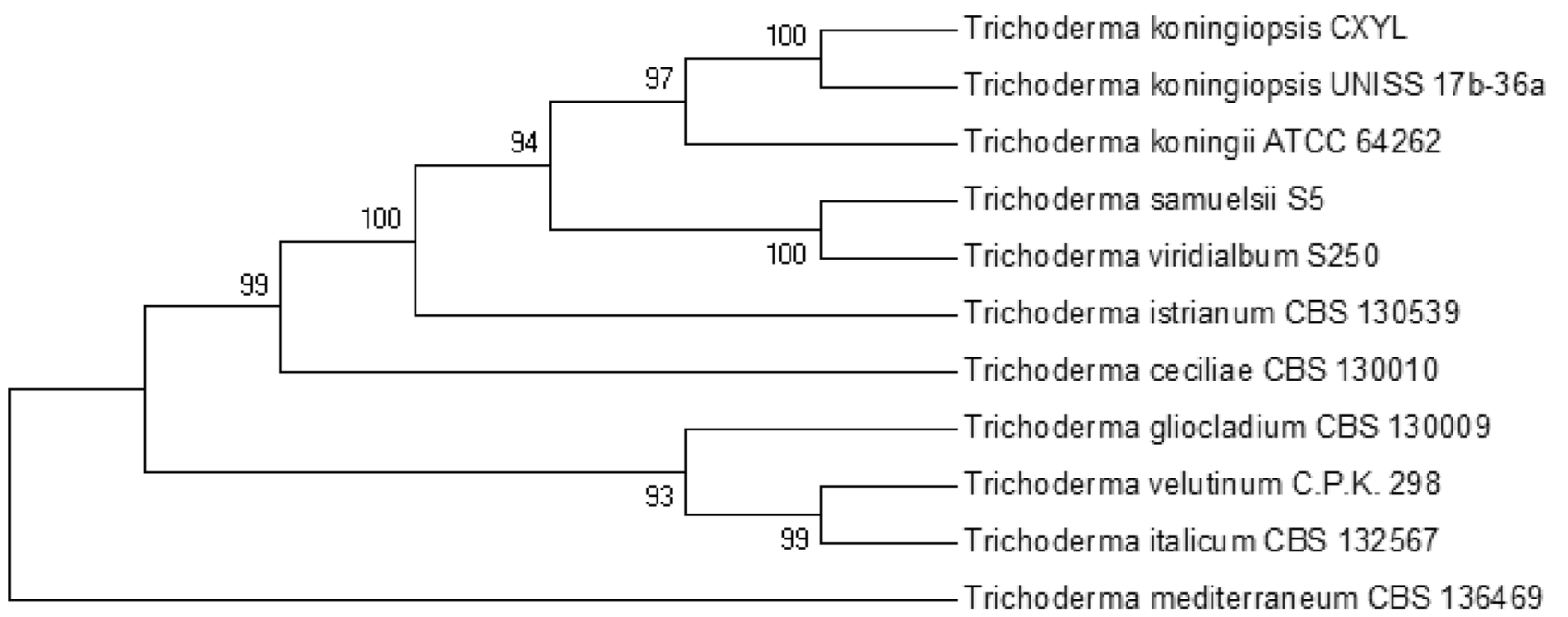

Fig. 2 Phylogenetic analysis of the ITS region and EF1- $\alpha$ gene sequences of T. koningiopsis CXYL from this study and reference sequences using the maximum likelihood method (1000 bootstrap iterations). Bootstrap values are provided next to the respective branches 
CXYL were isolated from D. rubrovolvata and verified by molecular analysis.

Similar to other Trichoderma spp., T. koningiopsis strains are considered as potential biocontrol agents against plant disease, as well as plant growth promoters (López et al. 2019; Yu et al. 2020). However, Trichoderma spp. are also common pathogens on mushrooms (Choi et al. 2010; Colavolpe et al. 2015; Kim et al. 2019). They can seriously influence the yield and quality of mushrooms during their cultivation, and thus significantly reduce the economic value in largescale productions. For instance, T. koningiopsis strain DC3 was reported as a destructive pathogen on Pleurotus eryngii (Kim et al. 2013). To our knowledge, this is the first report of $T$. koningiopsis as a pathogen on D. rubrovolvata causing green mold disease. Due to the high nutritional, medical, and economic value of $D$. rubrovolvata (Sun et al. 2017; Wang et al. 2020), the identification of the causal agent provides a relevant background for disease management in the future. In addition, the identification adds news insights related to the host range of T. koningiopsis, as it raises a serious biosafety concern when applied in biocontrol practices.

\section{Credit authorship contribution statement}

Xiaoyulong Chen \& Tomislav Cernava: Conceptualization, Methodology, Investigation, Validation, Supervision, Funding acquisition, Writing — original draft. Xiaohui Zhou, Jin Zhao, and Xiaoli Tang: Data curation, Formal analysis, Visualization. Matias Pasquali, Quirico Migheli, and Gabriele Berg: Methodology, Investigation, Writing — review \& editing.

Supplementary information The online version of this article (https:// doi.org/10.1007/s42161-021-00861-x) contains supplementary material, which is available to authorized users.

Funding Open access funding provided by Graz University of Technology. this study was supported by the National Key Research and Development Program of China (2021YFE0107700), Guizhou Provincial Science and Technology Program (20201Y124, 2019-1410, 20205001), Outstanding Young Scientist Program of Guizhou Province (KY2021026). In addition, the study received support by the Eurasia Pacific Uninet program (EPU 14/2019) and Program for Introducing Talents to Chinese Universities (111 Program, D20023).

\section{Declarations}

Ethical approval This article does not contain any studies with human participants or animals performed by any of the authors.

Declaration of competing interest The authors declare that they have no conflict of interest.

Open Access This article is licensed under a Creative Commons Attribution 4.0 International License, which permits use, sharing, adaptation, distribution and reproduction in any medium or format, as long as you give appropriate credit to the original author(s) and the source, provide a link to the Creative Commons licence, and indicate if changes were made. The images or other third party material in this article are included in the article's Creative Commons licence, unless indicated otherwise in a credit line to the material. If material is not included in the article's Creative Commons licence and your intended use is not permitted by statutory regulation or exceeds the permitted use, you will need to obtain permission directly from the copyright holder. To view a copy of this licence, visit http://creativecommons.org/licenses/by/4.0/.

\section{References}

Carbone I, Kohn LM (1999) A method for designing primer sets for speciation studies in filamentous ascomycetes. Mycologia 91:553-556

Choi IY, Choi JN, Sharma PK, Lee WH (2010) Isolation and Identification of Mushroom Pathogens from Agrocybe aegerita. Mycobiology 38:310-315

Colavolpe MB, Mejía SJ, Albertó E (2015) Efficiency of treatments for controlling Trichoderma spp during spawning in cultivation of lignicolous mushrooms. Braz J Microbiol 45:1263-1270

Kim JY, Kwon HW, Lee DH, Ko HK, Kim SH (2019) Isolation and characterization of airborne mushroom damaging Trichoderma spp. from indoor air of cultivation houses used for oak wood mushroom production using sawdust media. Plant Pathology $\mathrm{J}$ 35:674-683

Kim SW, Kim S., Lee HJ, Park JW, Ro HS (2013) Isolation of fungal pathogens to an edible mushroom, Pleurotus eryngii, and development of specific ITS primers. Mycobiology 41:252-255

Liu YJ, Whelen S, Hall BD (1999) Phylogenetic relationships among ascomycetes: evidence from an RNA polymerase II subunit. Mol Biol Evol 16:1799-1808

López AC, Alvarenga AE, Zapata PD, Luna MF, Villalba LL (2019) Trichoderma spp. from Misiones, Argentina: effective fungi to promote plant growth of the regional crop Ilex paraguariensis St. Hil Mycology 10:210-221

Sun L, Bao C, Chang W, Zhuang Y (2017) Preparation, characterisation, antioxidant and antiglycation activities of the novel polysaccharides from the pileus of Dictyophora rubrovolvata. Int J Food Sci Tech 52:161-170

Wang YX, Shi X, Yin JY, Nie SP (2018) Bioactive polysaccharide from edible Dictyophora spp.: Extraction, purification, structural features and bioactivities. Bioact Carbohydr Diet Fibre 14:25-32

Wang YX, Yin JY, Huang XJ, Nie SP (2020) Structural characteristics and rheological properties of high viscous glucan from fruit body of Dictyophora rubrovolvata. Food Hydrocolloid 101:105514

White TJ, Bruns T, Lee S, Taylor J (1990) Amplification and direct sequencing of fungal ribosomal RNA genes for phylogenetics. In: Innis MA, Gelfand DH, Sninsky JJ, White TJ (eds) PCR Protocols: A guide to methods and applications. Academic Press, San Diego, USA, pp 315-322

Ye JF, Luo P, Xiao JY, Wu XY, Zhang Y (2016) Induction of Dictyophora rubrovolvata polysaccharides on tumor cell apoptosis. Mycosystema 35:892-896

Yu C, Luo X (2020) Trichoderma koningiopsis controls Fusarium oxysporum causing damping-off in Pinus massoniana seedlings by regulating active oxygen metabolism, osmotic potential, and the rhizosphere microbiome. Biol Control 150:104352

Publisher's Note Springer Nature remains neutral with regard to jurisdictional claims in published maps and institutional affiliations. 